\title{
Birth injury: a possible contributory factor in the aetiology of primary basilar impression
}

\author{
ROBERT DE BATTERSBY, BERNARD WILLIAMS \\ From the Midland Centre for Neurosurgery and Neurology, Smethwick, West Midlands, UK
}

SUMMARY Adult patients with primary basilar impression were four times more likely to have a history of birth injury than a control group. Distortion of basicranial synchondroses during birth is suggested as a possible mechanism and, in association with hindbrain herniation and arachnoid adhesions, may contribute towards the development of syringomyelia.

Previous studies indicate that adult patients with syringomyelia are more likely to give a history of difficult labour, than a similar group of adults unaffected by syringomyelia. ${ }^{12}$ Abnormalities of the basiocciput and cervical spine, including basilar impression, are associated with cerebellar tonsillar herniation through the foramen magnum. Such a downward protrusion may be referred to as cerebellar ectopia, a cerebellar cone, hindbrain hernia, ArnoldChiari deformity or malformation, Chiari type II deformity or perhaps most simply as the Chiari anomaly. ${ }^{2}$ Such a hindbrain hernia, sometimes with arachnoiditis and sometimes with bony abnormalities at the skull base are frequently found in patients with syringomyelia. $^{3-7}$ Significant deformation of the cranium during delivery can lead to intracranial birth trauma. Deformity of the basicranium has been described in neonatal necropsy studies after difficult birth particularly following breech deliveries. ${ }^{8}$

The possibility exists therefore that significant structural abnormality of the basicranium may occur during labour, which remains compatible with life but leads to invagination of the foramen magnum and disease processes in the associated structures. In later life this may be detectable as basilar impression, atlanto-occipital assimilation, or indentation of the occiput behind the foramen magnum, sometimes called nuchal impression. This study compares the presence of primary basilar impression in adults with details of their birth history, to investigate whether a difficult labour is related to the development of primary basilar impression.

Address for reprint requests: RDE Battersby, Department of Neurosurgery, Royal Hallamshire Hospital, Glossop Rd, Sheffield S10 2JF, UK.

Received 27 February 1982 and in revised form 12 June 1982. Accepted 6 July 1982

\section{Method}

Seventy-seven patients with primary basilar impression were investigated. Primary basilar impression as used in this study is defined as the height in millimetres of the tip of the odontoid process above Chamberlain's line. ${ }^{9}$ Patients with basilar impression related to "acquired" conditions such as Paget's disease, rickets, achondroplasia, osteogenesis imperfecta and hyperparathyroidism, and those with basilar erosion due to rheumatoid arthritis have been excluded. ${ }^{10}$ Thus, in the groups studied, basilar impression may be due to a genetic predisposition to the deformity (none of these patients had a known familial tendency to basilar impression), an intra-uterine factor influencing the growth of the basicranium, or to factors occurring during labour. Measurements of primary basilar impression were performed on lateral skull radiographs, or lateral midline tomograms, using an identical technique for each patient.

Previous radiological studies of basilar impression suggest the position of the tip of the odontoid process has a normal distribution with relation to Chamberlain's line. Bull et al cite three series of patients, including their own, where the mean position of the tip of the odontoid process with relation to Chamberlain's line, varied from $-2.86 \mathrm{~mm}$ to $+0.06 \mathrm{~mm}$, with standard deviation ranging from $3.0 \mathrm{~mm}$ to $3.6 \mathrm{~mm} .{ }^{11}$ They have only considered cases as showing primary basilar impression when the tip of the odontoid process lay greater than $7 \mathrm{~mm}$ above Chamberlain's line, and noted its occurrence in those with and without neurological symptoms. Cases were included for analysis in this study when the tip of the odontoid process lay either on or above Chamberlain's line as it was felt that the "normal" radiological distribution may be influenced by birth trauma.

Sixty-two patients $(80 \%)$ had syringomyelia. The remainder either had symptomatic anomalies or were found to have coincidental asymptomatic primary basilar impression. All patients completed a birth history questionnaire. This recorded details of their birth known to be associated with risk to the foetus and a scoring system gave points to factors such as prolonged labour, high birth weight, forceps and breech delivery. Details are given by Williams. ${ }^{1}$ A control group of 205 patients, with neither 
basilar impression nor syringomyelia also completed a birth scoring questionnaire.

\section{Results}

The principal results are summarised in the table and the distribution of primary basilar impression is shown in fig 1 .

\section{BIRTH SCORE}

Fifty-seven per cent. of patients in the primary basilar impression group had a birth score of 1 or more compared to $23 \%$ in the control group (fig 2). Statistical analysis reveals a highly significant difference between the birth scores found in each group (chi square $=106.73$ with 3 degrees of freedom; $p<<0.001$ ). Assessment of relative risks shows that the likelihood of having a birth score amongst those with primary basilar impression compared to the control group was $4 \cdot 36: 1$, within 95\% confidence limits. Although a birth score was more likely in the primary basilar impression group, there was no correlation between the magnitude of the birth score and the degree of primary basilar impression.

\section{BIRTH ORDER}

Forty-four per cent. of patients in the primary basilar impression group were first born compared to $25 \%$ in the control group. A higher proportion of first born patients occurred in the primary basilar impression group compared to the control group (chi square $=$ $10 \cdot 29$ with 1 degree of freedom; $p<0 \cdot 01$ ). There was no correlation between birth order and the degree of primary basilar impression.

Table Results of the study

\begin{tabular}{|c|c|c|c|}
\hline & & Basilar impression & Controls \\
\hline $\begin{array}{l}\text { Total number of } \\
\text { patients } \\
\text { Male } \\
\text { Female } \\
\text { Mean age }(y r)\end{array}$ & & $\begin{array}{l}77 \\
34 \\
43 \\
43\end{array}$ & $\begin{array}{r}205 \\
108 \\
97 \\
40\end{array}$ \\
\hline $\begin{array}{l}\text { Birth score } \\
\text { Mean birth score }\end{array}$ & $\begin{array}{l}0 \\
1 \\
2 \\
3+\end{array}$ & $\begin{array}{lc} & \% \\
33 & (43) \\
15 & (19) \\
13 & (17) \\
16 & (21) \\
1.3 & \end{array}$ & $\begin{array}{cc} & \% \\
157 & (77) \\
23 & (11) \\
16 & (8) \\
9 & (4) \\
0.4 & \end{array}$ \\
\hline $\begin{array}{l}\text { Birth order } \\
\text { Mean birth order }\end{array}$ & $\begin{array}{l}1 \\
2 \\
3 \\
4+\end{array}$ & $\begin{array}{cc} & \% \\
34 & (44) \\
11 & (14) \\
19 & (25) \\
13 \\
2 \cdot 5\end{array}$ & $\begin{array}{cc} & \% \\
50 & (25) \\
45 & (22) \\
43 & (21) \\
66 & (32) \\
3.0 & \end{array}$ \\
\hline
\end{tabular}

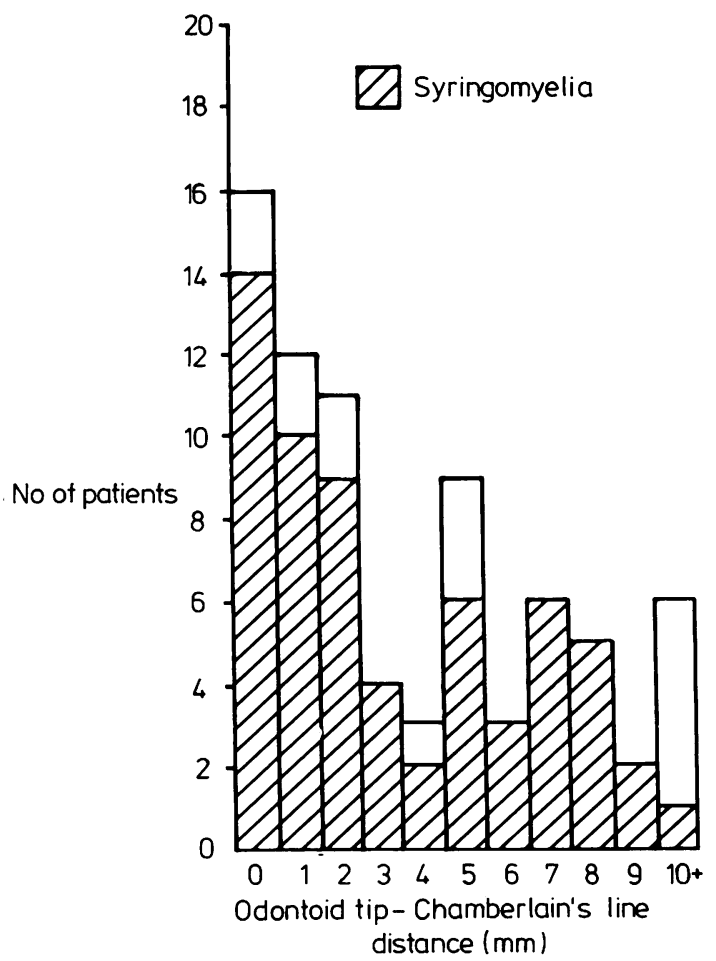

Fig 1 Frequency distribution of primary basilar impression.

\section{Discussion}

Birth trauma leading to injury in the craniovertebral region is well documented. Overriding of the squamous and lateral portions of the developing occipital bone (occipital osteodiastasis) can occur. ${ }^{8}$ Neonatal fractures of the occipital bone extend from the margins of the occipital bone down towards the basal portions. ${ }^{12}$

During breech delivery it has been suggested that occipital osteodiastasis is caused by pressure from the symphysis pubis against the suboccipital region, but it may also occur during forcible engagement of the head. In addition, injury to the cervical spinal cord and medulla, deformation and distortional trauma to the cervical spine and vertebral arteries have been described. ${ }^{13}$ Shulman et al mention 24 cases of spinal cord injury following cephalic delivery, and describe a case following mid forceps rotation which sustained atlanto-axial and atlanto-occipital dislocation with fracture of the odontoid process. ${ }^{14}$ Thus there is evidence that abnormal forces can occur during labour at the craniovertebral region sufficient to disrupt soft tissues and deform bony structures. These may have been caused by expulsive forces 


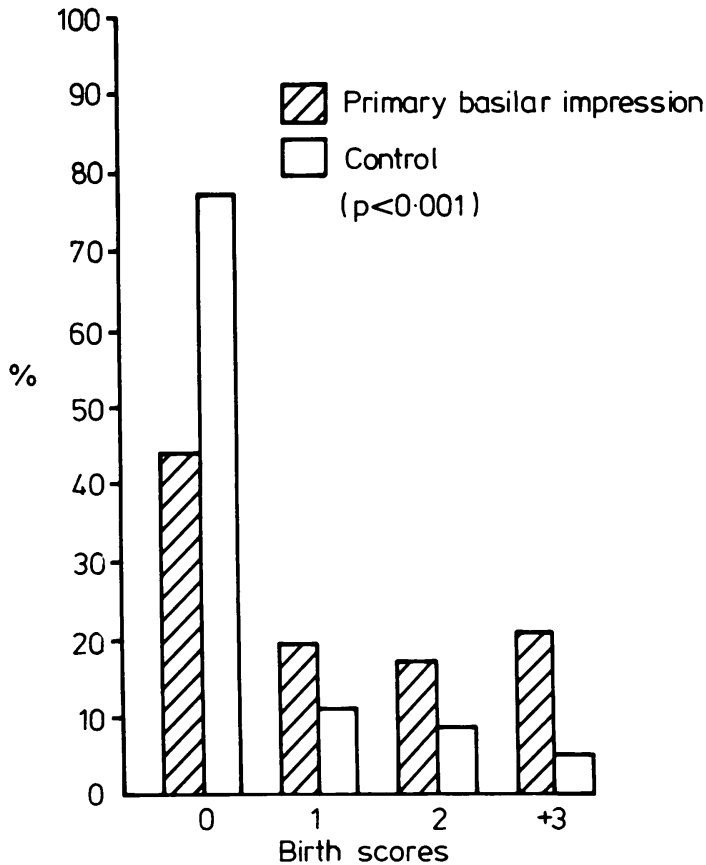

Fig 2 Higher birth scores found in adults with primary basilar impression compared to a control group.

acting along the long axis of the body or possibly by obstetric manoeuvres.

The growth and development of the basicranium is dependent on several factors including lengthening of the midbrain and brainstem, enlargement of the cerebral hemispheres and development of the facial structures, producing cranial base flexure. The flat basicranium of the neonate normally develops into the markedly curved basicranium of the adult. The basisphenoid and the occipital bone, excepting the squamous part above the nuchal line, develop from cartilage which is formed from condensations of mesenchymal cells appearing during the fifth to sixth week of intra-uterine life. Ossification centres appear in the cartilage between the sixth to eighth week. At birth the basal, lateral, and squamous portions of the occipital bone, and the basisphenoid are linked by the remaining cartilage as the strategically placed growth synchondroses, which persist after birth (fig 3). The squamous and lateral portions unite about the end of the second year at the posterior synchondrosis, and incorporation of the basiocciput in the sixth year by fusion at the anterior synchondrosis, completes the union of the occipital bone (fig 4). Fusion at the spheno-occipital synchondrosis is complete by the twenty-fifth year. ${ }^{15}$ A synchondrosis allows lengthening of bone in a field of direct compression

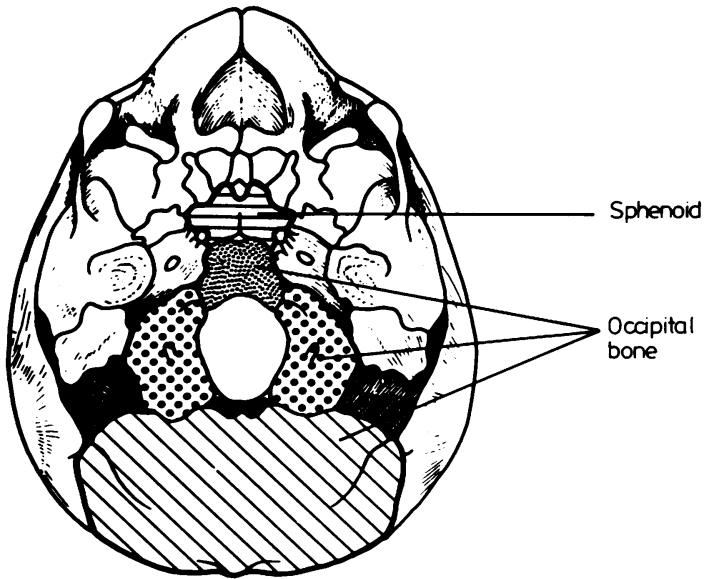

Fig 3 Diagrammatic representation of the neonatal basicranium.

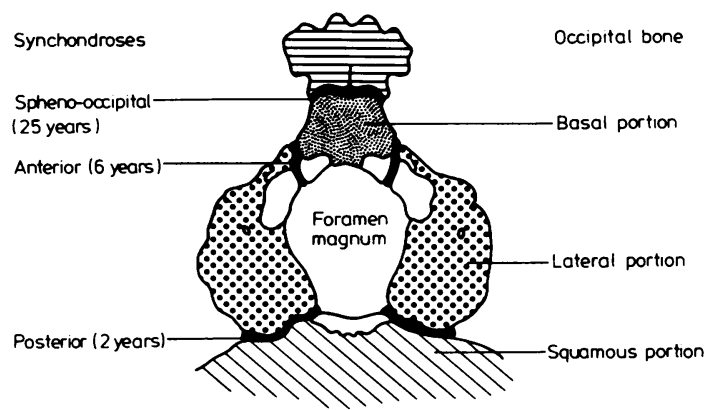

Fig 4 Diagrammatic representation of the foramen magnum region and adjacent structures in the neonatal basicranium. Components of the developing occipital bone are shown, and their linkage by strategically placed growth synchondroses. (Times of approximate closure in parenthesis.)

from the weight of the expanding brain, affecting particularly the midline portions of the basicranium. ${ }^{16}$ In adults with basilar impression elevation of the floor of the posterior fossa is most prominent medially. ${ }^{17}$ Subsequent growth and remodelling of the basicranium to produce an enlarged, flexed cranial base is substantially influenced by these synchondroses.

Wigglesworth and Husemeyer suggest that occipital osteodiastasis may be more common than is generally recognised and that it may not invariably prove fatal. ${ }^{8}$ It may be missed unless a particular necropsy routine is followed. Kruyff, describing eight cases of infantile occipital dysplasia analysed radiographically, noted in each case that the posterior synchondrosis was bilaterally or unilaterally absent, indicating pre- 
mature fusion. Premature synostosis of an anterior synchondrosis was also occasionally seen. ${ }^{18}$ McRae studying patients with basilar impression or platybasia or both noted that in addition to a convex clivus there was often a hump at the site of the sphenooccipital synchondrosis. ${ }^{4}$ It was suggested that early closure of the synchondrosis or hypoplasia of the basiocciput contributed to the platybasia. It is therefore conceivable that abnormal pressure on the developing basicranium during labour, insufficient to lead to death of the neonate might nonetheless deform or disrupt normal growth patterns leading to permanent deformity of the basicranium in adult life.

O'Connell and Turner describing cases of primary basilar impression found no associated congenital skeletal deformities and no evidence to suggest that primary basilar impression should be regarded as a congenital developmental anomaly. ${ }^{19}$ They suggested "the deformity might be due to mechanical factors alone in the presence of structural weakness of the weight transmitting area of the skull base", and offered an explanation for the characteristic deformity found in basilar impression by studying the architecture of the region of the occipito-atlantoid joints. Owing to the position and relative lack of support of the anterior margin of the occipital condyles, the anterior margin of the foramen magnum and basiocciput would be most affected. They concluded: "The unexplained feature is the factor which causes the skull base to give way ... it is possible that different types of congenital or acquired structural abnormality in bone or cartilage could be responsible".

The results of the present analysis show that patients in whom primary basilar impression is detected in adult life have a higher proportion of significant injury than a control group. This finding supports the hypothesis that an abnormal or difficult labour may contribute to or be responsible for some cases of primary basilar impression possibly by disrupting normal growth and development of the basicranium. If primary basilar impression were caused by primary deformation of the basicranium which persisted into adult life, rather than disruption of synchondroses without severe deformation it would be expected that more severe birth trauma would produce more severe degrees of basilar impression. This is not the case in this study, as increasing severity of birth trauma does not appear to affect the degree of primary basilar impression. As discussed earlier severe spatial deformation in the craniovertebral region often causes severe neurological damage, usually incompatible with life. Lesser degrees of injury to the basicranium, sufficient to distort synchondroses and interfere with normal growth and development of the basicranium, but insufficient to produce severe spatial deformation and therefore compatible with survival, may be the factor causing the skull base to give way to which O'Connell and Turner alluded. The basicranium, thus weakened during birth, might progressively deform during life until fusion of the elements constituting the base of the skull had occurred. Alteration of biomechanical conditions by various kinds of stress including previous disruption can influence time of closure of transplanted synchondroses in animals. ${ }^{2021}$ The higher proportion of first born children in the primary basilar impression group would be expected to have a relatively higher risk of birth injury than subsequent births.

Birth trauma is not the only factor causing primary basilar impression, but may be an additional influence in the development of this deformity or in some instances be a sufficient and only cause. Familial and racial factors may also be important. ${ }^{112223}$ Recent experimental work suggests that a primary para-axial mesodermal insufficiency, could affect the developing embryo. ${ }^{23}$ The administration of a single dose of vitamin $A$ to pregnant hamsters induces various types of axial skeletal dysraphic disorders, including hindbrain herniation with protrusion of the odontoid process into the cranial cavity related to the downward depression of the under developed basiocciput. Hormonal status also influences closure of basicranial synchondroses. ${ }^{25}$ Recognition of the possibility that a difficult labour may lead to primary basilar impression, possibly other craniovertebral deformities, and subsequent adult neurological abnormalities warrants early detection of the deformity to enable effective preventive treatment. Increasing sophistication of ultrasound techniques and computed axial tomography, should enable early atraumatic investigation of deformities of the basicranium following difficult labour. Modern obstetric practice differs considerably from the techniques employed forty years ago when trial of labour was safer than Caesarean section, and injury to the basicranium may now be uncommon. Newman et al, analysing cases from Newcastle, suggest that "superficially" the hypothesis that birth injury is aetiologically related to syringomyelia requires a diminishing incidence of syringomyelia in parallel with improving obstetric standards. The standard of resuscitation and neonatal care of damaged and premature infants is also improving, however, and it is possible that more babies are surviving after suffering a degree of damage sufficient to produce arachnoiditis, transient hydrocephalus, deformation of the skull base, anoxia with brain swelling and so on.

The Newcastle group suggested that the aetiology of syringomyelia probably requires a hindbrain 
hernia to be present at the time of birth and tend to favour the concept of a pre-existing embryonic abnormality. The most telling objection to this might be that in their series "Chiari with syrinx" was more than three times as common as Chiari anomaly on its own, in contrast to the proportion of normal birth to abnormal birth which were almost equal. It may be that there are more patients with asymptomatic Chiari anomaly than is normally suspected but it seemed more likely to Williams ${ }^{\prime}$ that the Chiari malformation was also a result of the birth injury. It might be that mild birth injury, sometimes so slight as to escape detection in a retrospective survey, may give rise to hindbrain herniation but that more severe birth injury gives more marked Chiari anomaly with an increased likelihood of arachnoiditis and therefore of syringomyelia.

Another possibility which deserves consideration is that bony deformation at birth causes the tonsils to herniate and that the herniation may persist due to pressure changes intermittently present throughout life even if the healing process of the infant allow the bony abnormalities to be corrected. No correlation between arachnioiditis, syringomyelia, primary basilar impression and birth injury has been attempted in the present analysis but continuing investigation along these lines seems indicated. Only by detailed investigation of the hindbrain area in neonates is the full picture likely to emerge.

\section{References}

' Williams B. Difficult labour as a cause of communicating syringomyelia. Lancet 1977;ii:51-3.

${ }^{2}$ Newman PK, Terenty TR, Foster PK. Some observations on the pathogenesis of syringomyelia. J Neurol Neurosurg Psychiatry 1981; 44:964-9.

${ }^{3}$ Hertel G, Nadjmi M, Kunze J. A statistical comparative study of the basilar impression in syringomyelia. Eur Neurol 1974; 11:363-72.

${ }^{4}$ McRae DL. Bony abnormalities in the region of the foramen magnum; correlation of the anatomic and neurologic findings. Acta Radiol (Stockh) 1953;40:33554.

${ }^{5}$ Logue V. Syringomyelia: a radiodiagnostic and radiotherapeutic saga. Clin Radiol 1971;22:2-16.

- Gustafson WA, Oldberg E. Neurological significance of platybasia. Arch Neurol Psychiatry 1940;44:1184-98.

${ }^{7}$ Gardner WJ. Hydrodynamic mechanism of syringomyelia: its relationship to myelocoele. $J$ Neurol Neurosurg Psychiatry 1965;28:247-59.

${ }^{8}$ Wigglesworth JS, Husemeyer RP. Intracranial birth trauma in vaginal breech delivery: The continued importance of injury to the occipital bone. Br J Obstet Gyn 1977;84:684-91.

${ }^{9}$ Chamberlain WE. Basilar impression (platybasia); A bizarre developmental anomaly of the occipital bone and upper cervical spine with striking and misleading neurological manifestations. Yale J Biol Med 1939; 11:487-96.

${ }^{10}$ Dolan KD. Cervicobasilar relationships. Radiol Clin $N$ Am 1977;15:160-6.

$"$ Bull JWD, Nixon WLB, Pratt RTC. The radiological criteria and familial occurrence of primary basilar impression. Brain 1955;78:229-47.

12 Chasler CN. The newbom skull: the diagnosis of fracture. Am J Roentgenol Radium Ther Nucl Med 1967;100: 92-9.

${ }^{13}$ Jones EL. Birth trauma and the cervical spine. Arch Dis Child 1970;45:147.

${ }^{14}$ Shulman ST, Madden JD, Esterley JR, Shanklin DR. Transection of spinal cord. A rare obstetrical complication of cephalic delivery. Arch Dis Childh 1971;46:291-4.

is Burdi AR. Early development of the human basicranium. In: Bosma JF, ed. Symposium on Development of Basicranium. DHEW Publication No. (NIH) 76-989. 1976:Ch 5.

${ }^{16}$ Enlon DH. Prenatal and post natal growth of human basicranium. In: Bosma JF, ed. Symposium on Development of Basicranium. DHEW Publication No. (NIH) 76-989. 1976:Ch 12.

17 Zingessor LH. Radiological aspects of the upper cervical spine and craniocervical junction. Clin Neurosurg 1973;20:220-31.

${ }^{18}$ Kruyff E. Occipital dysplasia in infancy. Radiology 1965;85:501-7.

${ }^{19}$ O'Connell JEA, Aldren Turner JW. Basilar impression of the skull. Brain 1950;73:405-26.

${ }^{20}$ Kylämarkula S, Rönning $O$. Transplantation of a basicranial synchondrosis to a sutural area in the isogeneic rat. Eur J Orthod 1979;1:145-53.

${ }^{21}$ Rönning $\mathrm{O}$, Kylämarkula S. Reactions of transplanted neurocentral synchondroses to different conditions of mechanical stress. A methodological study on the rat. J Anat 1979;128:789-801.

${ }^{22}$ Klaus E. Die familiare form der basilaren impression. Schweiz Arch Neur Neuroch Psychiat 1969;104(1): $31-42$.

${ }^{23}$ Caetano De Barros $M$ et al. Basilar impression and Arnold-Chiari malformation. J Neurol Neurosurg Psychiatry 1968;31:596-605.

${ }^{24}$ Marin Padilla M, Marin Padilla TM. Morphogenesis of experimentally induced Arnold-Chiari malformation. J Neurol Sci 1981;50:29-55.

${ }^{25}$ Asling CW, Simpson ME, Li CH, Evans HM. The effects of chronic administration of thyroxin to hypophysectomised rats on their skeletal growth, maturation and response to growth hormone. Anatomical Record 1954;119:101-18. 